\title{
Tridentate Schiff base (ONO) transition metal complexes: Synthesis, crystal structure, spectroscopic and larvicidal studies
}

\author{
SUNDARAMURTHY SANTHA LAKSHMI ${ }^{\mathrm{a}, *}$, KANNAPPAN GEETHA $^{\mathrm{b}}$ and P MAHADEVI ${ }^{\mathrm{a}}$

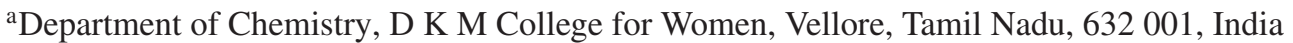 \\ ${ }^{b}$ Department of Chemistry, Muthurangam Government Arts College, Vellore, Tamil Nadu, 632 002, India \\ e-mail: santhalakshmi_s@yahoo.com
}

MS received 20 February 2016; revised 4 May 2016; accepted 6 May 2016

\begin{abstract}
A series of four new Schiff base transition metal complexes [Co(II), $\mathrm{Ni}(\mathrm{II}), \mathrm{Cu}(\mathrm{II})$ and $\mathrm{Zn}$ (II)] derived from $\mathrm{N}$-(salicylidene)-L-alanine and N,N,N',N'-tetramethylethylene-1,2-diamine (tmen) were designed, synthesized and tested for larvicidal activity against Culex quinquefasciatus, the southern house mosquito, which is the primary vector of St. Louis encephalitis virus and West Nile virus. All the complexes were characterized by physicochemical and spectral studies such as UV-Visible, FTIR, and EPR. The X-ray crystallographic analysis of $\mathrm{Ni}$ (II) complex revealed that, $\mathrm{Ni}$ (II) cation is surrounded by nitrogen and oxygen atoms from the Schiff base ligand, the oxygen atom of a water molecule, and two nitrogen atoms from tmen. Intermolecular hydrogen bonding stabilizes the $\mathrm{Ni}(\mathrm{II})$ complex. Results indicated that all the complexes exhibited higher mosquito larvicidal activity against $C$. quinquefasciatus.
\end{abstract}

Keywords. Single crystal XRD; octahedral; hydrogen bonding; mosquito larvicidal activity.

\section{Introduction}

Currently, coordination chemistry occupies a larger area of inorganic research. Transition metal complexes derived from Schiff bases have attracted attention of the researchers for the industry as well as biological applications. ${ }^{1}$ Amino acids are the important biological organic compounds and they are very good chelators and can readily form Schiff bases when treated with aromatic aldehydes and ketones. The Schiff bases derived from amino acids and $o$-hydroxy aldehydes or ketones are tridentates. ${ }^{2-4}$ Structural studies on binary and ternary Schiff base metal complexes derived from amino acids and salicylaldehyde show a variety of structures as monomers, dimers and polymers. ${ }^{5-7}$ Transition metal complexes of amino acid Schiff bases are showing interesting antimicrobial, antipyretic and DNA cleavage activities. ${ }^{8-11}$

Mosquitoes are the best known disease vector, transmit harmful diseases such as filariasis, chikungunya, dengue and encephalitis. ${ }^{12}$ Culex, the common house mosquito are the vectors for transmission of serious diseases, including West Nile virus, yellow fever, lymphatic filariasis and malaria. ${ }^{13}$ According to the report of WHO, over one million people worldwide die from mosquito borne diseases every year. Hence it is most urgent to discover new insecticides, especially against

\footnotetext{
*For correspondence
}

mosquitoes. As much attention has not been paid to explore biological activities of the amino acid Schiff base metal chelates derived from aliphatic chelating diamines, we synthesizes bioactive transition metal complexes derived from $\mathrm{N}$-(salicylidene)-L-alanine and tmen. All the new complexes were characterized by spectroscopic techniques. Single crystal X-ray crystallographic analysis of $\mathrm{Ni}(\mathrm{II})$ complex was done to elucidate the structure further. The biological activities of the Schiff base and the metal complexes were tested against the larvae of $C$. quinquefasciatus. The results revealed that the new complexes showed good activity against C. quinquefasciatus.

\section{Experimental}

\subsection{Materials and Physical Measurements}

All the reagents and chemicals were procured from commercial sources and used without further purification. Metal salts such as copper(II) acetate monohydrate, zinc(II) acetate dihydrate, nickel(II) acetate tetrahydrate and cobalt(II) acetate tetrahydrate were purchased from Sigma Aldrich. N,N,N'N'-tetramethylethylene1,2-diamine and salicylaldehyde were procured from Drug House (P) Ltd.

Molar conductance of the complexes was measured in DMF $\left(10^{-3} \mathrm{M}\right)$ solution using a direct digital 
conductometer. Magnetic susceptibility measurements were measured using Guoy balance at room temperature. FTIR spectra of solid complexes were recorded using $\mathrm{KBr}$ pellet in the region of $4000-400 \mathrm{~cm}^{-1}$ on an AVATAR-330 spectrophotometer. UV-Visible spectra of the complexes in DMF were recorded in the region of 200-800 nm using a HitachiU-2800 spectrophotometer. EPR spectra of the complexes were recorded in the solid state at room temperature using a Bruker EMX -10/2.7 spectrometer.

\subsection{Synthesis}

To an aqueous solution of L-alanine $(0.445 \mathrm{~g}, 5 \mathrm{mmol})$ and $\mathrm{KOH}(0.5625 \mathrm{~g}, 10 \mathrm{mmol})$, an ethanolic solution of salicyladehyde $(0.5 \mathrm{ml}, 5 \mathrm{mmol})$ was added. The reaction mixture was stirred for about $1 \mathrm{~h}$ in a magnetic stirrer at $333 \mathrm{~K}$. The solution turned yellow. To this an ethanolic solution, appropriate metal salt [copper(II) acetate monohydrate (1.1 g, $5 \mathrm{mmol})$, cobalt(II) acetate tetrahydrate $(1.25 \mathrm{~g}, 5 \mathrm{mmol})$, nickel(II) acetate tetrahydrate $(1.25 \mathrm{~g}, 5 \mathrm{mmol})$ and zinc(II) acetate dihydrate $(1.11 \mathrm{~g}, 5 \mathrm{mmol})]$ was added and the reaction mixture was stirred for $1 \mathrm{~h}$. Then, N,N,N'N'- tetramethylethylene-1,2-diamine $(0.3 \mathrm{~mL}, 5 \mathrm{mmol})$ was added in drops and the mixture was stirred for another $2 \mathrm{~h}$ at the same temperature. The resultant product was filtered, washed with ethanol and dried.

The analytical data of the complexes are as follows: $\mathbf{C}_{\mathbf{1 6}} \mathbf{H}_{\mathbf{2 7}} \mathbf{O}_{\mathbf{4}} \mathbf{N}_{\mathbf{3}} \mathbf{C o}$ : MW: 384.34; M.p. (decomp.): $220^{\circ} \mathrm{C} ; \Lambda_{\mathrm{M}}=3 \Omega^{-1} \mathrm{~cm}^{2} \mathrm{~mol}^{-1}$; Elemental analysis (\% Found /calculated): C: 51.47/50.0; H: 7.83/7.08; $\mathrm{N}: 11.48 / 10.93$. $\mathbf{C}_{\mathbf{1 6}} \mathbf{H}_{\mathbf{2}} \mathbf{O}_{\mathbf{4}} \mathbf{N}_{\mathbf{3}} \mathbf{N i}: \mathrm{MW}: 384.10$; M.p. (decomp.): $295^{\circ} \mathrm{C} ; \Lambda_{\mathrm{M}}=4.56 \Omega^{-1} \mathrm{~cm}^{2} \mathrm{~mol}^{-1}$; Elemental analysis (\% Found/calculated): C: 51.50/50.03; H: 6.83/7.09; N: 11.19/10.94. $\mathbf{C}_{\mathbf{1 6}} \mathbf{H}_{27} \mathbf{O}_{\mathbf{4}} \mathbf{N}_{\mathbf{3}} \mathbf{C u}$ : MW: 388.95; M.p. (decomp.): $186^{\circ} \mathrm{C} ; \Lambda_{\mathrm{M}}=4.56 \Omega^{-1} \mathrm{~cm}^{2} \mathrm{~mol}^{-1}$; Elemental analysis (\% Found /calculated): C: 50.82/49.41; $\mathrm{H}:$ 7.65/7.00; N: 10.95/10.80. $\mathbf{C}_{\mathbf{1 6}} \mathbf{H}_{\mathbf{2 7}} \mathbf{O}_{\mathbf{4}} \mathbf{N}_{\mathbf{3}} \mathbf{Z n}: \mathrm{MW}$ : 390.73; M.p. (decomp.): $128^{\circ} \mathrm{C} ; \Lambda_{\mathrm{M}}=3.41 \Omega^{-1} \mathrm{~cm}^{2}$ $\mathrm{mol}^{-1}$; Elemental analysis (\% Found /calculated): C: 50.41/49.17; H: 7.41/6.96; N: 11.08/10.75.

\section{$2.3 X$-ray Crystallography}

Single crystal X-ray diffraction data of the Ni(II) complex were collected on a Bruker Apex-II diffractometer. The green colored crystal of the Ni(II) complex obtained by slow evaporation of the mother liquor, with the crystal size of $0.25 \times 0.22 \times 0.13 \mathrm{~mm}$ was mounted on a glass fiber and used for data collection. Crystal data were collected using graphite monochromatized Mo-K $\alpha$ radiation $(\lambda=0.71073 \AA)$. The structure was solved by direct methods using SHELXS-97 and refined by full-matrix least-squares techniques against $F^{2}$ using SHELXL-2014/7. ${ }^{14,15}$ A summary of pertinent crystal data along with further details of structure determination and refinement are given in table 1.

\subsection{Larvicidal bioassay}

Culex quinquefasciatus larvae were collected from the Zonal Entomological Research Centre, Vellore, Tamil Nadu, India. Larvicidal activities of the synthesized metal complexes and the Schiff base ligand were carried out against fourth instar larvae of Culex quinquefasciatus by the previously optimized procedure. ${ }^{16}$ The percentage of mortality is reported as the average of triplicates.

\section{Results and Discussion}

All the synthesized transition metal complexes are freely soluble in DMSO, DMF, ethanol and partially soluble in water at room temperature. The lower molar conductivity values $\left(3.41-4.56 \Omega^{-1} \mathrm{~cm}^{2} \mathrm{~mol}^{-1}\right)$ of $10^{-3} \mathrm{M}$ complexes in DMF substantiate the non-electrolytic nature. ${ }^{17}$

The Co(II) complex showed a magnetic moment of $4.74 \mathrm{BM}$, suggesting a high spin octahedral arrangement. ${ }^{18}$ The magnetic moment of Ni(II) complex was found to be $2.96 \mathrm{BM}$, which suggests an octahedral geometry and the value is within the expected range of 2.83-3.50 BM. ${ }^{19}$ The $\mathrm{Cu}$ (II) complex showed magnetic moment of $1.92 \mathrm{BM}$. The observed value is higher than the spin-only value of $1.73 \mathrm{BM}$. The $\mathrm{Zn}$ (II) complex is diamagnetic as expected for a $\mathrm{d}^{10}$ configuration.

\subsection{Crystal structure of Ni(II) complex}

The selected bond lengths and bond angles of the Schiff base Ni(II) complex are listed in table 2. The $\mathrm{Ni}(\mathrm{II})$ complex crystallizes in the monoclinic system, with the space group $C 2 / c$ and with the values $\mathrm{a}=$ $30.6834(11) \AA, b=10.4813(4) \AA, c=12.1983(4) \AA$ and $\alpha=90^{\circ}, \beta=106.0906(13)^{\circ}$ and $\gamma=90^{\circ}, \mathrm{V}$ $=3769.3(2) \AA^{3}, Z=4$. An ORTEP view of nickel(II) complex along with the atom numbering scheme is shown in figure 1.

The Ni(II) ion has a distorted octahedral geometry and is bonded to three oxygen atoms and three nitrogen atoms. The coordinating atoms are phenolate oxygen $(\mathrm{O} 2)$, a carboxylate oxygen atom (O3) and an imine nitrogen atom (N1) of the Schiff base, two nitrogen atoms (N2 and N3) of tmen, and an oxygen atom (O1) 
Table 1. Crystal data and structure refinement for Ni(II) complex.

\begin{tabular}{|c|c|}
\hline CCDC Deposition number & 1404754 \\
\hline \multicolumn{2}{|l|}{ Crystal data } \\
\hline Chemical formula & $\mathrm{C}_{32} \mathrm{H}_{54} \mathrm{~N}_{6} \mathrm{Ni}_{2} \mathrm{O}_{8}$ \\
\hline$M_{\mathrm{r}}$ & 768.23 \\
\hline Crystal system, space group & Monoclinic, $C 2 / c$ \\
\hline Temperature $(\mathrm{K})$ & 296 \\
\hline$a, b, c(\AA)$ & $30.6834(11), 10.4813(4), 12.1983$ (4) \\
\hline$\beta\left({ }^{\circ}\right)$ & $106.0906(13)$ \\
\hline$V\left(\AA^{3}\right)$ & $3769.3(2)$ \\
\hline$Z, \rho\left(\mathrm{g} \mathrm{cm}^{-3}\right)$ & $4,1.354$ \\
\hline Radiation type & Mo $K \alpha$ \\
\hline$\mu\left(\mathrm{mm}^{-1}\right)$ & 1.05 \\
\hline Crystal size (mm) & $0.35 \times 0.22 \times 0.10$ \\
\hline Data collection & Bruker APEX-II CCD diffractometer \\
\hline \multicolumn{2}{|l|}{ Diffractometer } \\
\hline Absorption correction & - \\
\hline $\begin{array}{l}\text { No. of measured, independent and } \\
\text { observed }[I>2 \sigma(I)] \text { reflections }\end{array}$ & $14445,3320,2899$ \\
\hline Rint & 0.019 \\
\hline$(\sin \theta / \lambda)_{\max }\left(\AA^{-1}\right)$ & 0.595 \\
\hline \multicolumn{2}{|l|}{ Refinement } \\
\hline$R\left[F^{2}>2 \sigma\left(F^{2}\right)\right], w R\left(F^{2}\right), S$ & $0.031,0.090,1.04$ \\
\hline No. of reflections & 3320 \\
\hline No. of parameters & 230 \\
\hline $\mathrm{H}$-atom treatment & $\begin{array}{l}\mathrm{H} \text { atoms treated by a mixture of independent } \\
\text { and constrained refinement }\end{array}$ \\
\hline$\rho_{\max }, \rho_{\min }\left(\mathrm{e} \AA^{-3}\right)$ & $0.70,-0.42$ \\
\hline Data completeness & 0.999 \\
\hline Theta(max) & 24.999 \\
\hline
\end{tabular}

Table 2. Selected bond lengths (A) and angles (deg) for the $\mathrm{Ni}$ (II) complex.

\begin{tabular}{lc}
\hline N1-Ni1 & $1.9985(19)$ \\
N2-Ni1 & $2.253(2)$ \\
N3-Ni1 & $2.133(2)$ \\
Ni1-O2 & $2.0090(15)$ \\
Ni1-O3 & $2.0431(15)$ \\
Ni1-O1 & $2.1171(18)$ \\
N1-Ni1-O2 & $90.75(7)$ \\
N1-Ni1-O3 & $81.79(7)$ \\
O2-Ni1-O3 & $172.34(6)$ \\
N1-Ni1-O1 & $94.44(8)$ \\
O2-Ni1-O1 & $92.62(7)$ \\
O3-Ni1-O1 & $86.25(7)$ \\
N1-Ni1-N3 & $177.11(8)$ \\
O2-Ni1-N3 & $90.90(7)$ \\
O3-Ni1-N3 & $96.63(7)$ \\
O1-Ni1-N3 & $87.86(8)$ \\
N1-Ni1-N2 & $95.03(8)$ \\
O2-Ni1-N2 & $93.73(7)$ \\
O3-Ni1-N2 & $88.70(7)$ \\
O1-Ni1-N2 & $168.51(8)$ \\
N3-Ni1-N2 & $82.49(8)$ \\
\hline
\end{tabular}

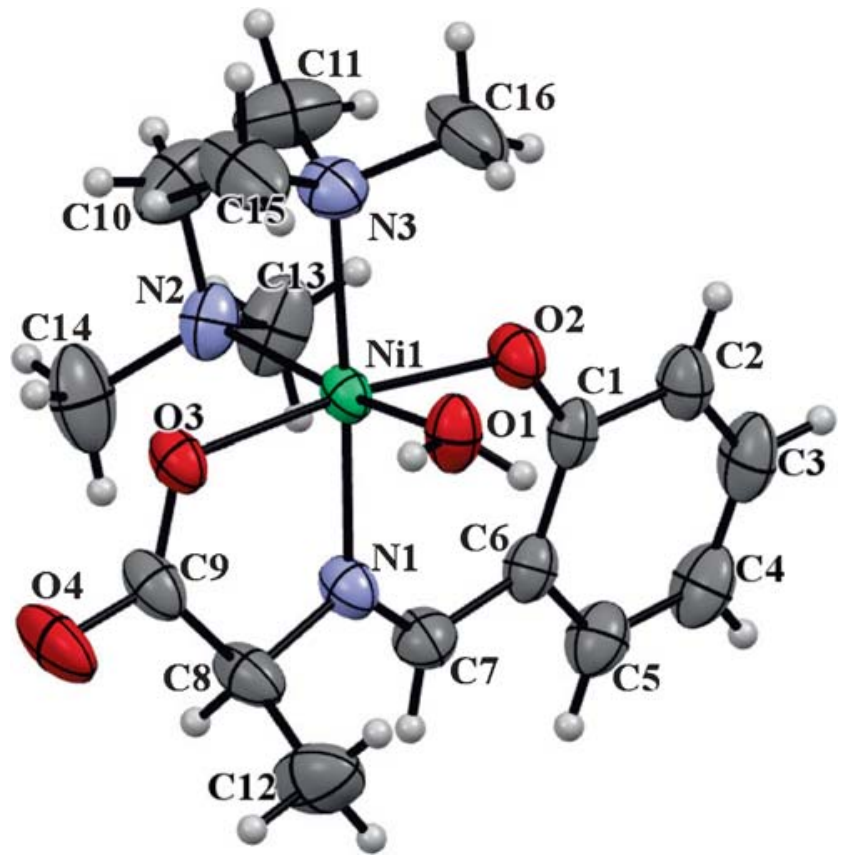

Figure 1. An ORTEP view of $\mathrm{Ni}(\mathrm{II})$ complex with the numbering scheme. 
of the water molecule. The Ni1-N2 (imine) [2.253(2) ̊] bond is longer than Ni1-N3 (tmen) [2.133(2) $\AA]$ and Ni1-N1 (tmen) [1.999(2) ̊] bonds. Among the Ni-O bonds, the Ni-O1 [2.117(2) $\mathrm{A}]$ bond to the coordinated oxygen atom of the water molecule is longer than the $\mathrm{Ni}-\mathrm{O} 2[2.009(2) \AA]$ and Ni-O3 [2.009(2) $\mathrm{A}]$ bonds.

\subsection{Crystal packing}

As shown in figure 2, the $\mathrm{O}-\mathrm{H} . . \mathrm{O}$ intermolecular hydrogen bonds are formed between the water molecule and the uncoordinated oxygen atom of the Schiff base ligand, along the symmetry coordinate $\mathrm{x}, \mathrm{y}, \mathrm{z}$. Along the c-axis, $\mathrm{Ni}(\mathrm{II})$ complex exhibits a butterfly shaped layered $2 \mathrm{D}$ chain with centrosymmetry due to hydrogen bonding. ${ }^{20}$ The crystal packing is effectively stabilized by the hydrogen-bonding interactions.

\subsection{Spectroscopic characterization}

The UV-Visible spectra of the Schiff base and the metal complexes (figure S1) were recorded at room temperature in DMF $\left(10^{-3} \mathrm{M}\right)$. The electronic spectral bands shown by the Schiff base ligand at $27,778 \mathrm{~cm}^{-1}$ and $37,037 \mathrm{~cm}^{-1}$ correspond to $\mathrm{n} \rightarrow \pi^{*}$ and $\pi \rightarrow \pi^{*}$ transitions of $\mathrm{C}=\mathrm{N}$ and aromatic chromophores,

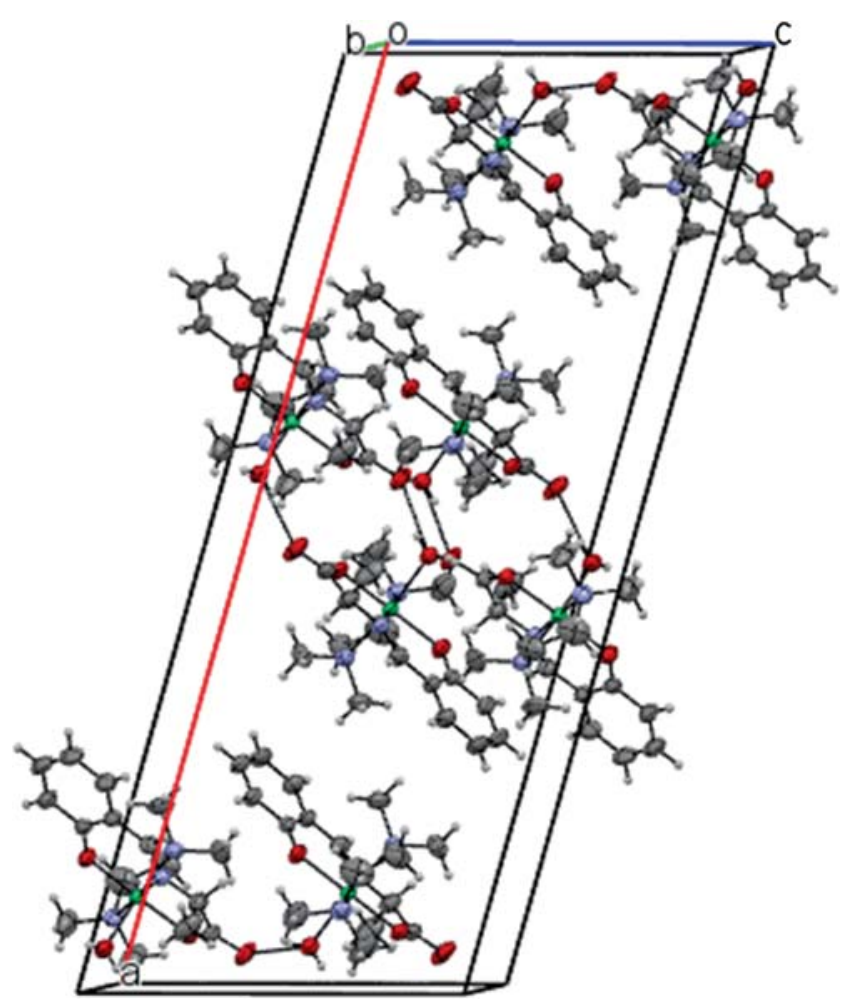

Figure 2. Crystal packing of $\mathrm{Ni}$ (II) complex viewed along b-axis. Intermolecular hydrogen bonding is shown in dotted lines. respectively. ${ }^{21}$ In the electronic spectrum of the Schiff base Co(II) complex, the bands observed at 15822 and $25974 \mathrm{~cm}^{-1}$ are assigned to ${ }^{4} \mathrm{~T}_{1 \mathrm{~g}}(\mathrm{~F}) \rightarrow{ }^{4} \mathrm{~A}_{2 \mathrm{~g}}(\mathrm{~F})$ and ${ }^{4} \mathrm{~T}_{1 \mathrm{~g}}(\mathrm{~F}) \rightarrow{ }^{4} \mathrm{~T}_{2 \mathrm{~g}}$ transitions, respectively, which are the characteristic bands for an octahedral geometry around $\mathrm{Co}(\mathrm{II})$ ion. $^{22}$

For an octahedral complex of $\mathrm{d}^{8}$ metal ions, the spinallowed transitions are ${ }^{3} \mathrm{~A}_{2 \mathrm{~g}} \rightarrow{ }^{3} \mathrm{~T}_{2 \mathrm{~g}}(\mathrm{~F}),{ }^{3} \mathrm{~A}_{2 \mathrm{~g}} \rightarrow{ }^{3} \mathrm{~T}_{1 \mathrm{~g}}(\mathrm{~F})$ and ${ }^{3} \mathrm{~A}_{2 \mathrm{~g}} \rightarrow{ }^{3} \mathrm{~T}_{1 \mathrm{~g}}(\mathrm{P})$. Accordingly, the electronic spectrum of the $\mathrm{Ni}(\mathrm{II})$ complex exhibited three absorption bands at $16,617 \mathrm{~cm}^{-1}, 25,510 \mathrm{~cm}^{-1}$ and $35,971 \mathrm{~cm}^{-1}$, thus providing an octahedral geometry around $\mathrm{Ni}(\mathrm{II})$ ion. ${ }^{18}$ For copper(II) complex, the band that appeared at $15,873 \mathrm{~cm}^{-1}$ is attributed to ${ }^{2} \mathrm{E}_{\mathrm{g}} \rightarrow{ }^{2} \mathrm{~T}_{2 \mathrm{~g}}$ transition. While, the band observed at $25,974 \mathrm{~cm}^{-1}$ is assigned to the charge transfer transition. ${ }^{23}$ The diamagnetic zinc(II) complex did not show any d-d transition. ${ }^{24}$ The charge transfer band of $\mathrm{Zn}$ (II) complex appeared at $26,954 \mathrm{~cm}^{-1}$ and an additional band appeared at $37,037 \mathrm{~cm}^{-1}$ which could be attributed to intraligand transition.

The characteristic FTIR spectral data of the complexes (figures S2 to S5 in Supplementary Information) are given in table 3 .

The FTIR spectra of all the complexes exhibited an intense band in the region $1598-1639 \mathrm{~cm}^{-1}$. This is attributed to the coordination of imine nitrogen with the metal ions. ${ }^{24}$ The coordinating mode of carboxylate groups can be investigated using FTIR spectra. For bidentate chelating or bridging mode the separation between $v_{\text {as }}\left(\mathrm{COO}^{-}\right)$and $v_{\mathrm{s}}\left(\mathrm{COO}^{-}\right)$of the carboxylate group is significantly less when compared to that of the free carboxylate anion value, while the separation is more than the free anionic value in case of unidentate mode. ${ }^{25,26}$ In the present case, the difference between asymmetric and symmetric stretching frequencies was found to be greater than that of free carboxylate anion $\left(185 \mathrm{~cm}^{-1}\right)$. This confirmed the monodentate coordination of the carboxylate anion present in the Schiff base ligand. All the complexes showed a broad band around $3200 \mathrm{~cm}^{-1}$, which confirms the presence of coordinated or lattice water molecule. ${ }^{23}$ The FTIR spectral band found between $1272-1291 \mathrm{~cm}^{-1}$ supported the coordination of phenolic oxygen with the metal ions. The bands that appeared in the range $450-480 \mathrm{~cm}^{-1}$ and $514-534 \mathrm{~cm}^{-1}$ confirmed the formation of M-O and M$\mathrm{N}$ coordination, respectively. ${ }^{27} \mathrm{In}$ accordance with the $\mathrm{X}$-ray crystallographic structure of $\mathrm{Ni}$ (II) complex, the FTIR spectral data of all the complexes revealed that the metal ion is coordinated through phenolic oxygen, imine nitrogen and oxygen atom present in the carboxylate group of the Schiff base ligand besides water molecule. 
Table 3. FTIR spectral data of the Schiff base metal complexes in $\mathrm{cm}^{-1}$.

\begin{tabular}{lcccccc}
\hline & & \multicolumn{2}{c}{$\mathrm{COO}^{-}$} & & & \\
\cline { 3 - 6 } Complex & $\mathrm{C}=\mathrm{N}$ & $\left(v_{\text {as }}\right)$ & $\left(v_{\mathrm{s}}\right)$ & $\Delta v=\left[v_{\text {as }-} v_{\mathrm{s}}\right]$ & $\mathrm{M}-\mathrm{O}$ & $\mathrm{M}-\mathrm{N}$ \\
\hline$\left[\mathrm{CoL}^{1} \mathrm{~L}^{2} \mathrm{X}\right]$ & 1598 & 1520 & 1319 & 201 & 476 & 534 \\
{$\left[\mathrm{NiL}^{1} \mathrm{~L}^{2} \mathrm{X}\right]$} & 1637 & 1558 & 1340 & 218 & 480 & 534 \\
{$\left[\mathrm{CuL}^{1} \mathrm{~L}^{2} \mathrm{X}\right]$} & 1639 & 1543 & 1327 & 216 & 468 & 514 \\
{$\left[\mathrm{ZnL}^{1} \mathrm{~L}^{2} \mathrm{X}\right]$} & 1623 & 1575 & 1344 & 231 & 450 & 520 \\
\hline
\end{tabular}

The paramagnetic nature of the complexes was investigated with the help of EPR spectroscopy. Except $\mathrm{Cu}$ (II) complex, all the other complexes were found to be EPR inactive at room temperature. Absence of EPR signal from zinc(II) complex could be attributed to the diamagnetic as expected for the $\mathrm{d}^{10}$ configuration of $\mathrm{Zn}(\mathrm{II})$. Due to large zero-field splitting, octahedral $\mathrm{Ni}(\mathrm{II})(\mathrm{S}=1)$ was found to be EPR inactive. ${ }^{28,29}$ The EPR spectrum of the $\mathrm{Cu}$ (II) complex (figure S6) in a polycrystalline state measured at room temperature exhibit an isotropic signal, without any hyperfine interaction with $g_{\text {iso }}$ value 2.1 . This value is greater than that of free electron and hence indicates an increase of the covalent nature of the bonding between the metal ion and the ligand. ${ }^{30}$ The Co(II) complex is EPR inactive at room temperature, as expected for octahedral geometry of high-spin complex. ${ }^{31}$

\subsection{Larvicidal activity}

The larvicidal activity of the complexes was performed against Culex quinquefasciatus and the values were noted. All the complexes showed moderate to stronger toxic effect against Culex quinquefasciatus. The percentage of mortality values of the complexes are listed in table 4.

The mortality was found after $24 \mathrm{~h}$ of exposure period for the Schiff base transition metal complexes. The highest mortality of $90 \%$ was observed for $\mathrm{Cu}$ (II) and $\mathrm{Ni}(\mathrm{II})$ complexes. The mortality of $\mathrm{Co}(\mathrm{II})$ and $\mathrm{Zn}$ (II) complexes were found to be $55 \%$ and $80 \%$, respectively. The average larval mortality data were subjected to statistical analysis for calculating standard deviation and chi-square values for synthesized metal complexes. The calculated values were lesser than table value hence, the results with $p<7.81$ were considered to be statistically significant.

\section{Conclusions}

In the present work, four new Schiff base transition metal complexes were synthesized and characterized by spectroscopic studies such as UV-Visible, FTIR, and EPR. The single crystal X-ray analysis of Ni(II) complex confirmed the distorted octahedral geometry around $\mathrm{Ni}(\mathrm{II})$ ion. Intermolecular O-H. . O hydrogen bonds between the water molecule and the noncoordinated oxygen atom of the Schiff base stabilize the molecular structure. Based on physicochemical and spectral studies, an octahedral geometry has been proposed for the other complexes. The results of in vitro larvicidal studies against $C$. quinquefasciatus revealed that the complexes possess effective larvicidal activity when compared to the Schiff base ligand. In particular, the $\mathrm{Cu}(\mathrm{II})$ and $\mathrm{Ni}$ (II) complexes showed potent activity against $C$. quinquefasciatus. Further investigations have to be carried out to establish the efficacy of larvicidal activities of these complexes.

Table 4. Statistical analysis of Schiff base and its metal complexes against fourth instar larvae of Culex quinquefasciatus.

\begin{tabular}{|c|c|c|c|c|c|c|c|c|}
\hline \multirow[b]{2}{*}{ Compound } & \multicolumn{4}{|c|}{ Concentration/\%Mortality \pm SD } & \multirow{2}{*}{$\begin{array}{c}\mathrm{LC}_{50} \\
\mathrm{mg} / 200 \mathrm{~L}\end{array}$} & \multirow{2}{*}{$\begin{array}{c}\mathrm{LC}_{90} \\
\mathrm{mg} / 200 \mathrm{~mL}\end{array}$} & \multirow[b]{2}{*}{$\chi^{2}$} & \multirow[b]{2}{*}{$\mathrm{df}$} \\
\hline & $4 \mathrm{mg} / 200 \mathrm{~mL}$ & $2 \mathrm{mg} / 200 \mathrm{~mL}$ & $1 \mathrm{mg} / 200 \mathrm{~mL}$ & $0.5 \mathrm{mg} / 200 \mathrm{~mL}$ & & & & \\
\hline$\left[\mathrm{CoL}^{1} \mathrm{~L}^{2} \mathrm{X}\right]$ & $55 \pm 6.29$ & $40 \pm 3.66$ & $20 \pm 1.5$ & $10 \pm 2.00$ & 2.7 & 4.86 & 13.76 & \\
\hline$\left[\mathrm{NiL}^{1} \mathrm{~L}^{2} \mathrm{X}\right]$ & $90 \pm 5.87$ & $65 \pm 5.27$ & $65 \pm 4.60$ & $25 \pm 15.45$ & 1.0 & 1.8 & 18.24 & 3 \\
\hline$\left[\mathrm{CuL}^{1} \mathrm{~L}^{2} \mathrm{X}\right]$ & $90 \pm 5.28$ & $50 \pm 6.28$ & $45 \pm 6.86$ & $30 \pm 4.75$ & 1.3 & 2.34 & 20.14 & \\
\hline$\left[\mathrm{ZnL}^{1} \mathrm{~L}^{2} \mathrm{X}\right]$ & $80 \pm 6.92$ & $55 \pm 6.19$ & $45 \pm 6.86$ & $25 \pm 15.45$ & 1.3 & 2.34 & 18.79 & \\
\hline $\mathrm{L}^{1}$ & $10 \pm 2.00$ & $0.5 \pm 0.00$ & 0 & 0 & 0 & 0 & 0 & \\
\hline
\end{tabular}

Mean value of triplicates; Control-Nil mortality; df- significant at $\mathrm{p}<7.81 ; \mathrm{LC}_{50}$-lethal concentration that kills $50 \%$ of the exposed larvae; $\mathrm{LC}_{90}$-lethal concentration that kills $90 \%$ of the exposed larvae. 


\section{Supplementary Information (SI)}

Supplementary X-ray crystallographic data for Ni(II) complex (CCDC 1404754) can be obtained free of charge via www.ccdc.cam.ac.uk/conts/retrieving.html (or from the Cambridge Crystallographic Data Centre, 12 Union Road, Cambridge CB2 1EZ, UK; Fax: $(+44)$ 1223-336-033 or e-mail: deposit@ccdc.cam.ac.uk). UV-Visible spectra (figure S1), FTIR (figures S2 to S5) and ESR (figure S6) of the complexes are given in Supplementary Information. Supplementary Information is available at www.ias.ac.in/chemsci.

\section{Acknowledgements}

The financial support for this work by University Grants Commission, India [MRP-5199/14 (UGC-SERO)] is gratefully acknowledged.

\section{References}

1. Ming Z W, Guan L C, Likun X, Jun J Y, Hong Y C, Zhao X M and Bo L L 2004 Chin. Chem. Lett. 15495

2. Ya-jin Y, Fei Y, Jing C, Hang-Li Z, Bian-Ling Y, Yin-Zhi J and Yang Z 2014 Inorg. Chim. Acta 41384

3. Ang L, Ya-Hong L, Ling-Zhi Y, Zhong-Ying M, Chun-Lai Z, Cheng-Zhi X, Wei-Guo B and Jing-Yuan X 2015 J. Inorg. Biochem. 14652

4. Rengaraj K, Sivasankar B, Anbu M and Palanichamy M 1991 Proc. Ind. Acad. Sci. (J. Chem. Sci.) 103707

5. Pattubala A N R, Riya D and Chakravarty A R $2000 \mathrm{~J}$. Chem. Sci. 112392

6. Werner P E, Valent A, Adelskold V and Svajlenova O 1983 Acta Chem. Scand. 37A 51

7. Palacios M S, Medina E, Manrique F G, Marnique M T, Gambardella P, Santos R H, Rodriguez M L and Dance J M 1989 Polyhedron 82132

8. Tieliang M, Jun X, Yuan W, Hao Y, Yong Y, Yang L, Weiliang D, Wenjiao Z, Ruhua C, Zhijun G, Yongfei T, Lei J and Taofeng Z 2015 J. Inorg. Biochem. 14438

9. Chakravarty A R 2006 J. Chem. Sci. 118443

10. Reddy P A N, Nethaji M and Akhil R C 2004 Eur. J. Inorg. Chem 1440
11. Samya B, Akanksha D, Sesha M K, Basudev M, Sanjoy M, Arun K, Anjali K and Chakravarty A R 2016 J. Chem. Sci. 128165

12. Rui W, Cong Z, Xiu-Jiang D, Li-Xia X, Shu-Jing Y, Xing-Hai L, Zheng-Ming L and Wei-Guang Z 2012 Chem. Cent. J. 699

13. Agrawal V K and Sashindran V K 2006 Med. J. Armed Forces India 62359

14. Sheldrick G M 2008 In SHELXS-97 Program for the Crystal Structure Refinement (Göttingen, Germany: University of Göttingen)

15. Sheldrick G M 2008 SHELXS-97 Program for the Crystal Structure Refinement (University of Göttingen: Göttingen, Germany)

16. Saranya J and Santha Lakshmi S 2015 J. Chem. Pharm. Res. 7180

17. Geary W J 1971 Coord. Chem. Rev. 781

18. Salman M S 2013 Arab. J. Chem. 6191

19. Chandra S 1985 Polyhedron 4663

20. Chris S H and Paul E K 2014 Crystals 432

21. Nan Z, Yu-Hua F, Zhen Z, Jian Z, Peng-Fei Z, Qiang W, Shan-Bin L and Cai-Feng B 2012 Inorg. Chem. Commun. 2268

22. Anacona J R, Natiana N and Juan C 2015 Spectrochim. Acta, Part A 13716

23. Kalagouda B G, Manjula S P, Ramesh S V, Rashmi V S and Siddappa A P 2006 Trans. Met. Chem. 31580

24. Selwin J R, Justin D C and Sivasankaran N M 2006 Trans. Met. Chem. 31699

25. Deacon B G and Phillips R J 1980 Coord. Chem. Rev. 33227

26. Ming X L, Min S, Hui D, Bao L A, Wen C L, Yu Z and Chen X D 2005 Chin. Chem. Lett. 161405

27. Nakamoto K 1978 In Infra-red and Raman Spectra of Inorganic and Coordination Compounds 3rd ed. (New York: John Wiley)

28. Prasad R L, Kushwaha A and Shrivastava O N 2012 J. Solid State Chem. 196471

29. Simon R C and Martin S 2006 In Encyclopedia of Inorganic Chemistry (New York: John Wiley) doi: 10.1002/ 0470862106.ia150

30. Angelusiu M V, Almanjan G L, Ilies D C, Rosu T and Negoiu M 2008 Chem. Bull. Politehnica Univ. Timisoara $\mathbf{5 3} 78$

31. Li C Z, Zhou S F, Fan X Z, Zhu Z F, Ding Y F, Zhao C H, Xia C G and Wang L F 2000 Chem. Pap. 54239 